Postprint of Food Control, Volume 91, September 2018, Pages 248-253

DOI: https://doi.org/10.1016/j.foodcont.2018.04.006

\title{
A survey of ethanol content in virgin olive oil
}

Lourdes García-Vico ${ }^{1}$, Angjelina Belaj ${ }^{2}$, Lorenzo León ${ }^{2}$, Raúl de la Rosa ${ }^{2}$, Carlos Sanz $^{1}$, Ana G. Pérez ${ }^{1}$

${ }^{1}$ Department of Biochemistry and Molecular Biology of Plant Products, Instituto de la Grasa, CSIC, Campus UPO, Ctra. Utrera km 1, Bldg 46, 41013-Seville, Spain.

${ }^{2}$ IFAPA, Centro Alameda del Obispo, Menéndez Pidal s/n, 14004-Cordoba, Spain.

AUTHOR E-MAIL ADDRESS:

Lourdes García-Vico: lourdesgarcia@ig.csic.es

Angjelina Belaj: angjelina.belaj@juntadeandalucia.es

Lorenzo León: lorenzo.leon@juntadeandalucia.es

Raúl de la Rosa: raul.rosa@juntadeandalucia.es

Ana G. Pérez: agracia@cica.es

CORRESPONDING AUTHOR FOOTNOTE

Carlos Sanz, Tel: +34-95-4611550, Fax: +34-95-616790,

e-mail: carlos.sanz@ig.csic.es 


\section{Abstract}

2 Ethanol is a substrate for the chemical synthesis of fatty acid ethyl esters (FAEE) during storage 3 of virgin olive oil whose contents are officially regulated. Given the impact that the ethanol 4 content might have on the olive oil commercialization, the level of this metabolite has been 5 studied in an array of olive genotypes representing the diversity available in olive (Olea europaea 6 L.). Substantial levels of ethanol have been found in the oils of all genotypes under study. 7 Moreover, increasing levels of alcohol dehydrogenase activity have been found during olive fruit 8 ripening in good correspondence with the accumulation of ethanol in advanced stages of fruit 9 maturation. The results suggest that ethanol has a ubiquitous character in the fruits of Olea 10 europaea and, therefore, in all the oils obtained from them. Besides, their concentration seems to 11 depend on the cultivar, ripening stage and climatology, not discarding the influence of the 12 growing conditions. Data suggest that the application of olive oil regulation for FAEE levels 13 should consider the presence of basal levels of ethanol in the oils, which are quite high in many 14 cultivars.

17 Keywords: Olea europaea L.; virgin olive oil; ethanol 


\section{Introduction}

Ethanol is a component that is naturally present in the olive fruit issues and, consequently, could pass into virgin olive oil (VOO) during the extraction process as it has been observed in a number of cultivars (Luna et al., 2006; Beltrán et al., 2015). The occurrence of ethanol in plants is generally associated to an adaptation to oxygen deprivation (Davies, 1980). It is produced from pyruvate by the consecutive action of pyruvate decarboxylase (PDC) and alcohol dehydrogenase $(\mathrm{ADH})$ enzymes (Fig. 1). However, the presence of this compound in plants is not necessarily related to a decrease in the availability of oxygen in the tissues as this pathway may work under aerobic conditions (i.e. aerobic fermentation) playing different key roles in the plant physiology. In adverse environmental conditions such as cold, drought or high $\mathrm{CO}_{2}$ concentrations, an increase of ethanol content in the plant tissues has been observed due to an induction of PDC and ADH gene expression (Tadege et al., 1999; Moyano et al., 2004). The aerobic fermentation pathway also participates actively in the strategies used by the different plants for the preservation of the species through seed dispersal. Thus, both PDC and ADH activities have been observed to increase during the strawberry fruit ripening parallel to the accumulation of sugars and the increase in the synthesis of aroma compounds, which corresponds largely to esters derived from ethanol (Pérez et al., 1992; Moyano et al., 2004). Unlike most of the fruits, the olive fruit uses a different strategy for seed dispersal. Olive fruit accumulates large amounts of triacylglycerol (TAG) along ripening, whose production in plants is carried out from the building block acetyl-CoA (Fig. 1). However, while acetyl-CoA is synthesized in seeds from pyruvate by the action of the enzymatic complex pyruvate dehydrogenase (PDH), the synthesis in olive fruit seems to be carried out from acetate through the so-called PDH bypass (Fig. 1), which is mediated by the acetyl-CoA synthetase (ACS) activity (Salas et al., 2000). In this pathway, pyruvate is previously transformed into acetate by the sequential action of PDC and aldehyde dehydrogenase (AlDH)(Fig. 1), as demonstrated to occur in photosynthetic tissues (Roughan \& Ohlrogge, 1996) and microalgae (Ramanan et al., 2013; Avidan \& Pick, 2015). According to this model, the $\mathrm{ADH}$ activity would function as a safety valve to protect the cell from the accumulation of the transient excess of the cytotoxic acetaldehyde through conversion into ethanol.

The presence of ethanol in the oil may represent a problem from the perspective of the VOO legislation as this compound is substrate for the chemical synthesis of fatty acid ethyl esters (FAEE) during VOO storage. FAEE is a quality parameter used for virgin olive oil (VOO) according to the European Commission and the International Olive Oil Council (European Commission Regulation, 2013; International Olive Oil Council, 2013). These compounds are produced during storage whenever there are free fatty acids and ethanol in the oil and its chemical synthesis is dependent on the content $\mathrm{s}$ of those substrates, temperature and time (Di

55 Loreto et al., 2014; Gómez-Coca et al., 2016). FAEE was originally proposed as a fraud indicator for the identification of blends with low quality oils such as those subjected to deodorization as 
do not originate exclusively in this process as it is also found in VOO obtained from non-sound fruits. In this sense, the relationship between the FAEE content in VOO and its sensory classification have been described in different studies (Gomez-Coca et al., 2012; Perez-Camino et al., 2002). More recently, Di Serio et al. (2017) demonstrated the relationship that exists between the FAEE level in the oil and the sensory defects caused by fermentative processes in the olive fruits. Thus, this parameter is today used as an indicator of the health status of the fruit from which the oil was extracted (Bendini et al., 2009; Mariani \& Bellan, 2008) based on the assumption that the presence of its substrate ethanol in the oil can solely be due to its generation in fermentative processes occurring in the fruit or in the oil (Bierdermann et al., 2008; Conte et al., 2014). This is the reason why EU Commission Regulation 1348/2013 (2013) substituted alkyl esters with ethyl esters. The former term also included originally the methyl esters (FAME), whose production in the oil uses as substrate the methanol present in the fruit. Unlike ethanol, the level of methanol in the fruit is considered to be physiological because methanol is liberated during the pectin degradation of the cell wall as olive fruit ripens.

It has been demonstrated that ethanol is not just a fermentation derivative as it accumulates in sound fruits during ripening (Beltran et al., 2015). The question is how much of the ethanol present in the oil is coming from the physiological levels in the olive fruit and how much is due to fermentative processes. Given the impact that the ethanol content might have, as substrate for the synthesis of FAEE, in the classification of olive oil as Extra-VOO and in line with the needs for research that Conte et al. (2014) suggested regarding the limits of the ethanol content in the oils, the aim of this work was to investigate the natural occurrence of ethanol in virgin olive oil and its genetic variability. For this purpose, a wide range of VOOs representing the available diversity of the olive species was screened. Moreover, the enzymatic activity responsible for the synthesis of ethanol in the olive fruit tissues was studied to verify its metabolic origin.

\section{Materials and methods}

2.1. Plant material.

Two sets of olive samples representative of the Olea europaea species were studied. On one hand, a collection of 97 commercial cultivars that gathered the genetic variability of the World Olive Germplasm Collection (WOGC) located at IFAPA Centre "Alameda del Obispo", (CAPUCO-IFAPA) in Cordoba Spain. Trees, two per accession, were cultivated in the same conditions at the WOGC using standard culture practices. On the other, 136 genotypes featuring the same genetic background, from the cross of olive cultivars 'Picual' and 'Arbequina', were also included in the study. The harvest was carried out by hand during four consecutive years (20092012) at turning stage except for the studies related to fruit ripening. Additionally, for 'Picual', 'Arbequina' and five genotypes from their cross (characterized by having quite different levels of volatile compounds in their oils), fruits were harvested at three ripening stages [ripening index $(\mathrm{RI})=1,2.5$ and 5] in order to test the influence of RI on ADH activity. 
2.2. Preparation of ADH crude extracts and enzymatic assay.

Preparation of crude extracts and measure of $\mathrm{ADH}$ activity were carried out according to Sánchez-Ortiz et al. (2012) with minor modifications. Acetone powders were prepared from the mesocarp of fresh harvested olive fruits by grinding with acetone at $-20{ }^{\circ} \mathrm{C}(1: 15$, w/v $)$ using a blender. After filtration, the residue was re-extracted twice with $20 \mathrm{~mL}$ of cold acetone. The whitish powder obtained was finally rinsed with diethylether, dried and stored at $-20{ }^{\circ} \mathrm{C}$. ADH enzyme extracts were prepared from $125 \mathrm{mg}$ of acetone powder in $3 \mathrm{~mL}$ of a buffer consisting of $50 \mathrm{mM}$ sodium phosphate ( $\mathrm{pH} 7.2), 14 \mathrm{mM} \beta$-mercaptoethanol, $2 \mathrm{mM}$ ditiothreitol and $10 \%$ glycerol using an Ultraturrax homogenizer $(3 \mathrm{x} 1 \mathrm{~min})$. The resulting homogenate was centrifuged at $27000 \mathrm{~g}$ for $20 \mathrm{~min}$ at $4{ }^{\circ} \mathrm{C}$ and filtered through Miracloth®. The clear supernatant was used as the crude extract.

ADH activity was assayed by mixing $1.5 \mathrm{ml}$ of $100 \mathrm{mM}$ sodium phosphate ( $\mathrm{pH} 6.0$ ), $30 \mu \mathrm{l}$ of $10 \mathrm{mM}$ reduced nicotinamide adenine dinucleotide (NADPH), $10 \mu \mathrm{l}$ of $1 \mathrm{M}$ hexanal and $20 \mu \mathrm{l}$ of the crude extract. ADH activity was measured by monitoring the decrease in absorbance at 340 $\mathrm{nm}$ over time due to the oxidation of NADPH. One unit of ADH activity is defined as the amount of enzyme required to oxidize $1 \mu \mathrm{mol}$ of NADPH per min at $25{ }^{\circ} \mathrm{C}$, taking into account a molar extinction coefficient of $6160 \mathrm{M}^{-1} \cdot \mathrm{cm}^{-1}$.

\subsection{Olive oil extraction.}

Olive oil was extracted from batches of $2-3 \mathrm{~kg}$ of olive fruits using an Abencor analyzer (Comercial Abengoa, S.A., Seville, Spain) that mimics the industrial process of VOO production on a laboratory scale (Martínez et al., 1975). Milling of the olive fruit was performed using a stainless steel hammer mill operating at $3000 \mathrm{rpm}$ and with a $5 \mathrm{~mm}$ sieve. The Abencor thermobeater was used for the malaxation step for $30 \mathrm{~min}$ at $28{ }^{\circ} \mathrm{C}$. Finally, centrifugation of the kneaded paste was carried out in a basket centrifuge at $3500 \mathrm{rpm}$ for $1 \mathrm{~min}$. After centrifugation, the oils were decanted, paper filtered, and stored under nitrogen at $-20{ }^{\circ} \mathrm{C}$ until they were analyzed.

\subsection{Analysis of ethanol in the oil.}

The content of ethanol in the oils was analyzed by means of HS-SPME/GC-MS-FID according to Pérez et al. (2016). Olive oil samples $(0.5 \mathrm{~g})$ were prepared in $10-\mathrm{mL}$ vials and were conditioned to room temperature and then placed in a vial heater at $40{ }^{\circ} \mathrm{C}$ for a $10 \mathrm{~min}$ equilibration time. Volatile compounds from the headspace were adsorbed onto SPME fiber DVB/CAR/PDMS 50/30 $\mu \mathrm{m}$ (Supelco Co., Bellefonte, PA). Sampling time was carried out at 40 ${ }^{\circ} \mathrm{C}$ for at least $50 \mathrm{~min}$, which is the time needed to reach the equilibrium. Desorption of volatile compounds was completed directly into the GC injector. Volatile compounds were identified out on a 7820A/GC-5975/MSD system (Agilent Technologies), equipped with a DB-Wax capillary column (60 $\mathrm{m} \times 0.25 \mathrm{~mm}$ i.d., film thickness, $0.25 \mu \mathrm{m}$ : J\&W Scientific, Folsom, CA) and under the following conditions: the injection port was operated in splitless mode at $250{ }^{\circ} \mathrm{C}$; He was 
used as the carrier gas and the flow rate was $1 \mathrm{~mL} / \mathrm{min}$; column was held for $6 \mathrm{~min}$ at $40{ }^{\circ} \mathrm{C}$ and then programmed at $2{ }^{\circ} \mathrm{C} \min ^{-1}$ to $168{ }^{\circ} \mathrm{C}$; the mass detector was operated in the electronic impact mode at $70 \mathrm{eV}$, the source temperature was set at $230{ }^{\circ} \mathrm{C}$ and the mass spectra were scanned at $2.86 \mathrm{scans} / \mathrm{s}$ in the $\mathrm{m} / \mathrm{z}$ 40-550 amu range. Compound identification was performed by matching against the Wiley/NBS Library, and by GC retention time against absolute ethanol (Sigma-Aldrich, St. Louis, MO). For quantitative purposes, the volatile fraction was analyzed three times on a HP-6890 GC equipped with a FID detector (Agilent Technologies) using also a DB-Wax capillary column operated under the following conditions to reproduce the same retention timea than those of the 7820A/GC-5975/MSD system: $\mathrm{N}_{2}$ was used as carrier gas at 17 psi constant pressure; injector and detector were held at $250{ }^{\circ} \mathrm{C}$; column was held for 6 min at 40 ${ }^{\circ} \mathrm{C}$ and then ramped up at $2{ }^{\circ} \mathrm{C} / \mathrm{min}$. Calibration curves were made in re-deodorized high-oleic sunflower oil and a linear regression curve was obtained $\left(\mathrm{R}^{2}=0.996\right)$.

\section{Results and discussion}

The ethanol content in oils from a large sample of genotypes representative of the Olea europaea species was studied. The sample covers around a quarter of the WOGC cultivars from IFAPA (Cordoba, Spain), including the Core-36 cultivars of the WOGC (Belaj et al., 2012) for guaranteeing a high genetic diversity, and a segregating progeny of the 'Picual' and 'Arbequina' cultivars having a similar genetic background. As described in Materials and Methods, the trees of these cultivars and the segregating progeny were grown under the same agronomic conditions and the fruits were hand-picked, transported at low temperature, and carefully washed prior to the immediate extraction of their oil. Thus, it was guaranteed that the oils were produced from apparently clean and healthy fruits. As shown in Figure 2, all the oils analyzed in these samples have been shown to contain ethanol. This ubiquity of ethanol in VOO would confirm the hypothesis made by Beltrán et al. (2015) that the ethanol, which is naturally found in the fruit, would later pass into the oil during the extraction process. The presence of ethanol in fruits is a common occurrence in many plant species, especially in those with fragrant fruits where large amounts of ethyl esters are synthesized during ripening and postharvest storage (Pérez et al., 1992; Moyano et al., 2004; Pérez \& Sanz, 2008, Bangerth et al., 2012). Actually, the results of the analyses have also shown that all the oils examined contained ethanol-related compounds such as its metabolic precursor, acetaldehyde, and the esterified product ethyl acetate (data not shown). However, contrary to the latter, ethanol has no impact on the aroma of olive oil, even in the case of higher contents, due to the extremely high odour threshold of this compound ( $30 \mu \mathrm{g} / \mathrm{g}$ oil) (Romero et al., 2015).

A content range of $0.12-12.93 \mathrm{mg} / \mathrm{kg}$ oil was found for ethanol among the WOGC cultivar subset under study, with an average value of $2.10 \mathrm{mg} / \mathrm{kg}$ oil. These levels are in agreement with those found by Romero et al. (2015) for oils of cultivars Arbequina, Hojiblanca and Manzanilla $(0.17-4.24 \mathrm{mg} / \mathrm{kg}$ oil) in a recent validation work of the HS-SPME/GC-MS method for the quantification of VOO volatile compounds. However, the same research group found higher 
contents of ethanol (20-24 mg/kg oil) in the oils of the Chetoui and Chemlali cultivars produced in Tunisia (Tena et al., 2007). Even greater contents were found by Tura et al. (2008) for oil samples obtained from 18 Italian olive cultivars grown in the western coast of the Garda lake (northern Italy). The mean content $(30.6 \mathrm{mg} / \mathrm{kg}$ oil) and content range $(3.47-217.7 \mathrm{mg} / \mathrm{kg}$ oil) were an order of magnitude higher than what was found in this study.

As stated by Gómez-Coca et al. (2016), the FAEE content in the oil is dynamic, proving that it increases with time under certain storage conditions and reaching the limits established by the European Commission Regulation (2016) in a few months. It has been estimated that $11 \%$ of the cultivars under study would have given rise to oils with ethanol contents which, considering a complete conversion in the most favorable storage conditions, lead to FAEE levels above 35 $\mathrm{mg} / \mathrm{kg}$ oil. These hypothetical FAEE levels would make those oils not to be considered as ExtraVOO according to the European Commission Regulation (2016) despite having been obtained with the best sanitary guarantees.

As in the WOGC cultivars, all the oils analyzed from the 'Picual' $x$ 'Arbequina' progeny contained ethanol, which would support the hypothesis that it is a ubiquitous component in VOO (Fig. 2-B). A high level of segregation was found among the genotypes of the progeny for the ethanol content, displaying even higher ethanol contents $(0.04-48.06 \mathrm{mg} / \mathrm{kg}$ oil) than those observed in the WOGC cultivars, clearly transgressing the levels found in the parents 'Arbequina' and 'Picual'. The average ethanol content in the cross progeny was also clearly higher than that found for the WOGC cultivars $(3.58 \mathrm{mg} / \mathrm{kg}$ oil versus $2.10 \mathrm{mg} / \mathrm{kg}$ oil). However, in both olive samples a median value of $0.8 \mathrm{mg} / \mathrm{kg}$ oil was found. It has been estimated that $18 \%$ of the 'Picual' $x$ 'Arbequina' progeny produced oils containing ethanol levels that could potentially lead to levels of FAEE above the VOO limit (FAEE > $35 \mathrm{mg} / \mathrm{kg}$ oil) established by the European Commission Regulation (2016), despite the fact that the oils were obtained in adequate sanitary conditions.

The content of ethanol in the oils must be contextualized in its harvest year, considering that this study has been developed over four years. In this sense, it has been investigated how the climatology of the year affects the level of ethanol in the oils from the two main cultivars grown in Spain, 'Picual' and 'Arbequina', and parents of the studied cross progeny. The content of ethanol in the oils varied depending on the season climatic conditions as displays in Figure 3-A. Interestingly, these cultivars do not follow the same pattern in the different seasons, as shown by the change in the proportions of the ethanol contents in the 2011 and 2012 seasons compared to those observed in the 2009 and 2010 seasons.

Another important aspect to be considered in this study is that the oils were obtained from olives at the turning stage (roughly RI = 2.5). As shown in Figure 3-B, the ethanol content follows different evolution patterns during the ripening process depending on the cultivar. Thus, while the oils of the 'Arbequina' cultivar show a slight increase in the ethanol content in the year of study, a strong increase was found for oils of the 'Picual' cultivar in advanced stages of ripening $(R I=5)$, approximately quadrupling the levels found in less advanced stages $(R I=1$ and 
2.5) to reach contents of $4.55 \mathrm{mg} / \mathrm{kg}$ oil. These levels coincide with those found by Beltrán et al. (2016) for this cultivar at the same stage of ripening. It should be noted that this ethanol content in the oil may potentially be converted, after storage under appropriate conditions, into FAEE contents dangerously close to the limit value marked by the VOO regulation for this parameter (European Commission Regulation, 2016).

Data demonstrated a substantial influence of the year climatology and the fruit ripening stage on the ethanol content in each cultivar, not ruling out the interaction between both variables and that derived from the growing conditions. The influence of fruit ripening stage on the ethanol content could be explained from a biochemical point of view. As shown in Figure 4-A, there is a good relationship between the level of ADH activity that synthesizes ethanol and the ethanol content in the oils (Fig. 3-B), experiencing an increase as ripening advances. The level of ADH activity was also studied during the ripening process of five genotypes from the 'Picual' $\mathrm{x}$ 'Arbequina' cross (Figure 4-B). As it happens to the two parents ('Picual' and 'Arbequina'), an increase in the level of this enzymatic activity was observed during fruit ripening for all the genotypes under study in good agreement with what found by Iaria et al. (2012) for the expression level of an olive ADH gene $(O e A D H)$. The confirmation of the natural presence of ethanol in $\mathrm{VOO}$, and consequently in olive fruits, and of $\mathrm{ADH}$ activity would indirectly support the hypothesis of the PDH bypass working in the generation of TAG in olive fruit; this ADH activity acting as a safety valve against the synthesis of high levels of acetaldehyde, which produces ethanol.

\section{Conclusions}

It has been investigated the presence of ethanol in the oils produced by individuals from two olive samples, commercial cultivars from WOGC and genotypes from a segregating population of the 'Picual' x 'Arbequina' cross, representative of the Olea europaea species. Data suggest that ethanol is naturally found in the fruits of the Olea europaea species and, therefore, in all oils obtained from them, and that its concentration is a function of the cultivar, ripening stage and year climatology, not ruling out the dependence of the growing conditions. The levels of ADH activity found in the olive fruit might explain its accumulation during fruit ripening. Despite the fact that the presence of ethanol in the oil may be related to fermentation processes, the application of olive oil regulation for FAEE levels should take into account the presence of basal levels of ethanol in the oils as it is quite high in many olive cultivars.

\section{Acknowledgement}

Funding for this research came from the OLEAGEN project of Genoma España and the project AGL2011-24442 from the Programa Nacional de Recursos y Tecnologías Agroalimentarias, both financed by the Spanish Government. The plant materials evaluated here were obtained from the cooperative breeding program carried out at the University of Cordoba, 
and at the Institute of Agricultural and Fishery Research and Training (IFAPA), Spain. We are grateful to Mar Pascual for her excellent technical assistance.

\section{References}

Avidan, O., \& Pick, U. (2015). Acetyl-CoA synthetase is activated as part of the PDH bypass in the oleaginous green alga Chlorella desiccate. Journal of Experimental Botany, 66, 72877298.

Bangerth, F. K., Song, J., \& Streif, J. (2012). Physiological impacts of fruit ripening and storage conditions on aroma volatile formation in apple and strawberry fruit: a review. HortScience, 47, 4-10.

Belaj, A., Dominguez-García, M. C., Atienza, S. G., Martín-Urdíroz, N., De la Rosa, R., Satovic, Z., Martín, A., Kilian, A., Trujillo, I., Valpuesta, V., \& Del Río, C. (2012). Developing a core collection of olive (Olea europaea L.) based on molecular markers (DArTs, SSRs, SNPs) and agronomic traits. Tree Genetics \& Genomes, 8, 365-378.

Beltrán, G., Bejaoui, M. A., Jiménez, A., \& Sánchez-Ortiz, A. (2015). Ethanol in olive fruit: changes during ripening. Journal of Agricultural and Food Chemistry, 63, 5309-5312.

Beltrán, G., Sánchez, R., Sánchez-Ortiz, A., Aguilera, M. P., Bejaouia, M. A., \& Jiménez, A. (2016). How 'ground-picked' olive fruits affect virgin olive oil ethanol content, ethyl esters and quality. Journal of the Science of Food and Agriculture, 96, 3801-3806

Bendini, A., Cerretani, L., Valli, E., Lercker, G., \& Mazzini, C. (2009). Metodi analitici per la determinazione di oli deodorati mild in oli extra vergini di oliva commerciali. Industrie Alimentari, 48, 46-51.

Biedermann, M., Bongartz, A., Mariani, C., \& Grob, K. (2008). Fatty acid methyl and ethyl esters as well as wax esters for evaluating the quality of olive oils. European Food Research and Technology, 228, 65-74.

Conte, L., Mariani, C., Gallina Toschi, T., \& Tagliabue, S. (2014). Alkyl esters and related compounds in virgin olive oils: their evolution over time. Rivista Italiana Delle Sostanze Grasse, 91, 21-29.

Davies, D.D. (1980). The biochemistry of plants, metabolism and respiration. (Vol 2) (pp. 581611). London/New York: Academic Press.

Di Loreto, G., Giansante, L., Alfei, B., \& Di Giacinto, L. (2014). Alchil esteri ed altri indicatori per la tutela della qualità e della genuinità degli oli extra vergini italiani. Rivista Italiana Sostanze Grasse, 91, 35-45.

Di Serio, M. G., Giansante, L., Di Loreto, G., Faberi, A., Ricchetti, L., \& Di Giacinto, L. (2017). Ethyl esters versus fermentative organoleptic defects in virgin olive oil. Food Chemistry, 219, 33-39.

European Commission (2013). EU 1348/2013 of 16 December 2013 amending Regulation No 2568/91/EEC on the characteristics of olive oil and olive-residue oil and on the relevant methods of analysis. Official Journal of the European Communities, L338, 31-67. 
European Commission (2016). EU 2016/2095 of e6 September 2016 amending Regulation No 2568/91/EEC on the characteristics of olive oil and olive-residue oil and on the relevant methods of analysis. Official Journal of the European Communities, L326, 1-6.

Gómez-Coca, R. B., Fernandes, G. D., Pérez-Camino, M. C., \& Moreda, W. (2016). Fatty acid ethyl esters (FAEE) in extra virgin olive oil: A case study of a quality parameter. $L W T$ - Food Science and Technology, 66, 378-383.

Gómez-Coca, R. B., Moreda, W., \& Pérez-Camino, M. C. (2012). Fatty acid alkyl esters presence in olive oil versus organoleptic assessment. Food Chemistry, 135, 1205-1209.

Iaria, D. L., Bruno, L., Macchione, B., Tagarelli, A., Sindona, G., Giannino, D., Bitonti, M. B., \& Chiapetta, A. (2012). The aroma biogenesis related Olea europaea alcohol dehydrogenase gene is developmentally regulated in the fruits of two $O$. europaea L. cultivars. Food Research International, 49, 720-727.

International Olive Oil Council (2013). Trade standard applying to olive oils and olive-pomace oils. COI 2013/T15/NC No 3/Rev. 17.

Luna, G., Morales, M.T., \& Aparicio, R. (2006). Characterisation of 39 varietal virgin olive oils by their volatile composition. Food Chemistry, 98, 243-252.

Mariani, C., \& Bellan, G. (2008). Individuazione di oli di qualità inferiore negli oli di oliva extravergini. Rivista Italiana Delle Sostanze Grasse, 1, 3-20.

Martínez, J. M., Muñoz, E., Alba, J., \& Lanzón, A. (1975). Report about the use of the 'Abencor' analyser. Grasas y Aceites, 26, 379-385.

Moyano, E., Encinas-Villarejo, S., López-Ráez, J. A., Redondo-Nevado, J., Blanco-Portales, R., Bellido, M. L., Sanz, C., Caballero, J. L., \& Muñoz-Blanco, J. (2004). Comparative study between two strawberry pyruvate decarboxylase genes along fruit development and ripening, post-harvest and stress conditions. Plant Science, 166, 835-845.

Pérez, A. G., \& Sanz, C. (2008). Formation of fruit flavor. In B. Bruckner, \& S.G. Wyllie (Eds.), Fruit and Vegetable Flavour (pp. 71-102). Boca Raton, FL: CRC Press.

Pérez, A. G., De la Rosa, R., Pascual, M., Sánchez-Ortiz, A., Romero-Segura, C., León, L., \& Sanz, C. (2016). Assessment of volatile compound profiles and the deduced sensory significance of virgin olive oils from the progeny of Picual x Arbequina cultivars. Journal of Chromatography A, 1428, 305-315.

Pérez, A. G., Ríos, J. J., Sanz, C., \& Olías, J. M. (1992). Aroma components and free amino acids in strawberry var. Chandler during ripening. Journal of Agricultural and Food Chemistry, 40, 2232-2235.

Pérez-Camino, M. C., Moreda, W., Mateos, R., \& Cert, A. (2002). Determination of esters of fatty acids with low molecular weight alcohols in olive oils. Journal of Agriculture and Food Chemistry, 50, 4721-4725.

Ramanan, R., Kim, B. H., Cho, D. H., Ko, S. R., Oh, H. M., \& Kim, H. S. (2013). Lipid droplet synthesis is limited by acetate availability in starchless mutant of Chlamydomonas reinhardtii. FEBS Letters, 587, 370-377. 
Romero, I., García-González, D.L., Aparicio-Ruiz, R., \& Morales, M.T. (2015). Validation of SPME-GCMS method for the analysis of virgin olive oil volatiles responsible for sensory defects. Talanta, 134, 394-401.

Roughan, P. G. \& Ohlrogge, J. B. (1996). Evidence that isolated chloroplasts contain an integrated lipid-synthesizing assembly that channels acetate into long-chain fatty acids. Plant Physiology, 110, 1239-1247.

Salas, J. J., Sánchez, J., Ramli, U. S., Manaf , A. M., Williams, M., \& Harwood, J. L. (2000). Biochemistry of lipid metabolism in olive and other oil fruits. Progress in Lipid Research, $39,151-180$.

Sánchez-Ortiz, A., Romero-Segura, C., Gazda, V. E., Graham, I. A., Sanz, C., \& Pérez, A. G. (2012). Factors limiting the synthesis of virgin olive oil volatile esters. Journal of Agricultural and Food Chemistry, 60, 1300-1307.

Tadege, M., Dupuis, I., \& Kuhlemeier, C. (1999). Ethanolic fermentation: new functions for an old pathway. Trends in Plant Science, 8, 320-325.

Tena, N., Lazzez, A., Aparicio-Ruiz, R., \& García-González, D.L. (2007). Volatile compounds characterizing Tunisian Chemlali and Chétoui virgin olive oils. Journal of Agricultural and Food Chemistry, 55, 7852-7858

Tura, D., Failla, O, Bassi, D, Pedo, S, \& Serraiocco, A. (2008). Cultivar influence on virgin olive (Olea europea L.) oil flavor based on aromatic compounds and sensorial profile. Scientia Horticulturae, 118, 139-148. 


\section{$351 \quad$ Figure captions}

353 Figure 1. Biochemical mechanisms for generating acetyl-CoA, precursor of the novo fatty acid 354 biosynthesis.

356 Figure 2. Content $(\mathrm{mg} / \mathrm{kg}$ oil) of ethanol in the oils produced from cultivars from the World 357 Olive Germplasm Collection (A) and from genotypes of the 'Picual' $x$ Arbequinal' cross (B). The 358 arrows mark individuals from which the ethanol content can potentially be converted into FAEE 359 levels higher than the limit established by the European Commission Regulation (2016).

360

361 Figure 3. Content $(\mathrm{mg} / \mathrm{kg}$ oil) of ethanol in oils from the cultivars 'Picual' and Arbequinal' 362 throughout the seasons 2009-2012 (A), and during the fruit ripening (B).

363

364 Figure 4. Levels of $\mathrm{ADH}$ activity (U/g fruit) during ripening of 'Picual' and Arbequinal' fruits 365 (A) and of fruits from selected genotypes of the 'Picual' $x$ Arbequinal' cross (B). 


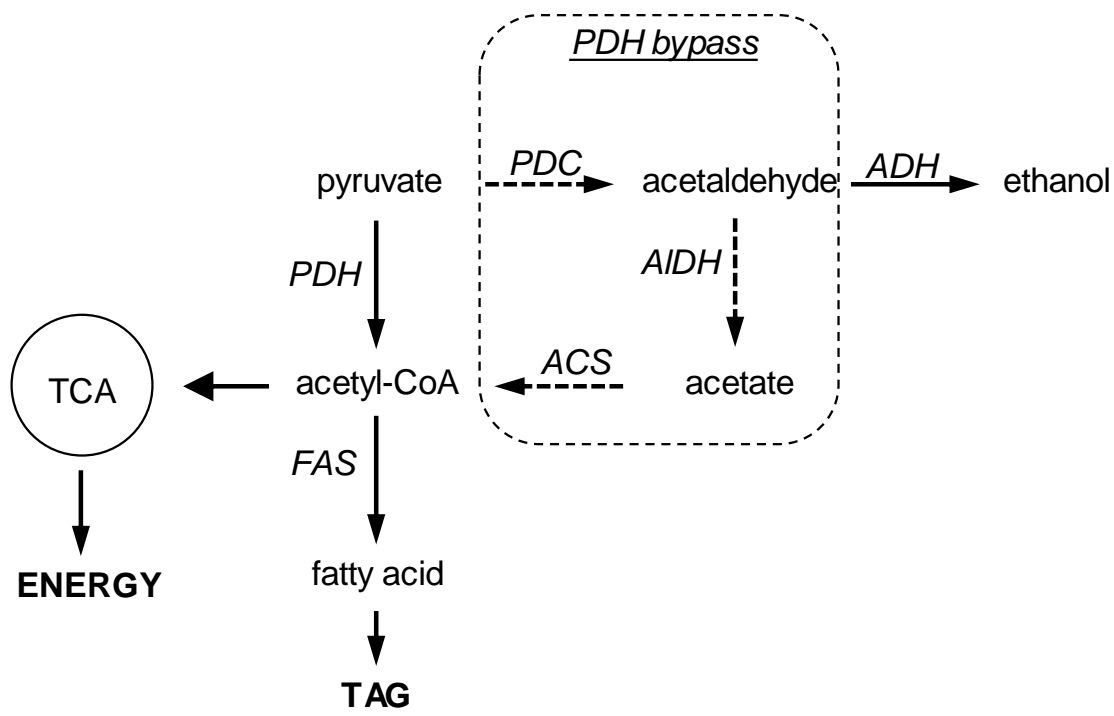

Figure 1 

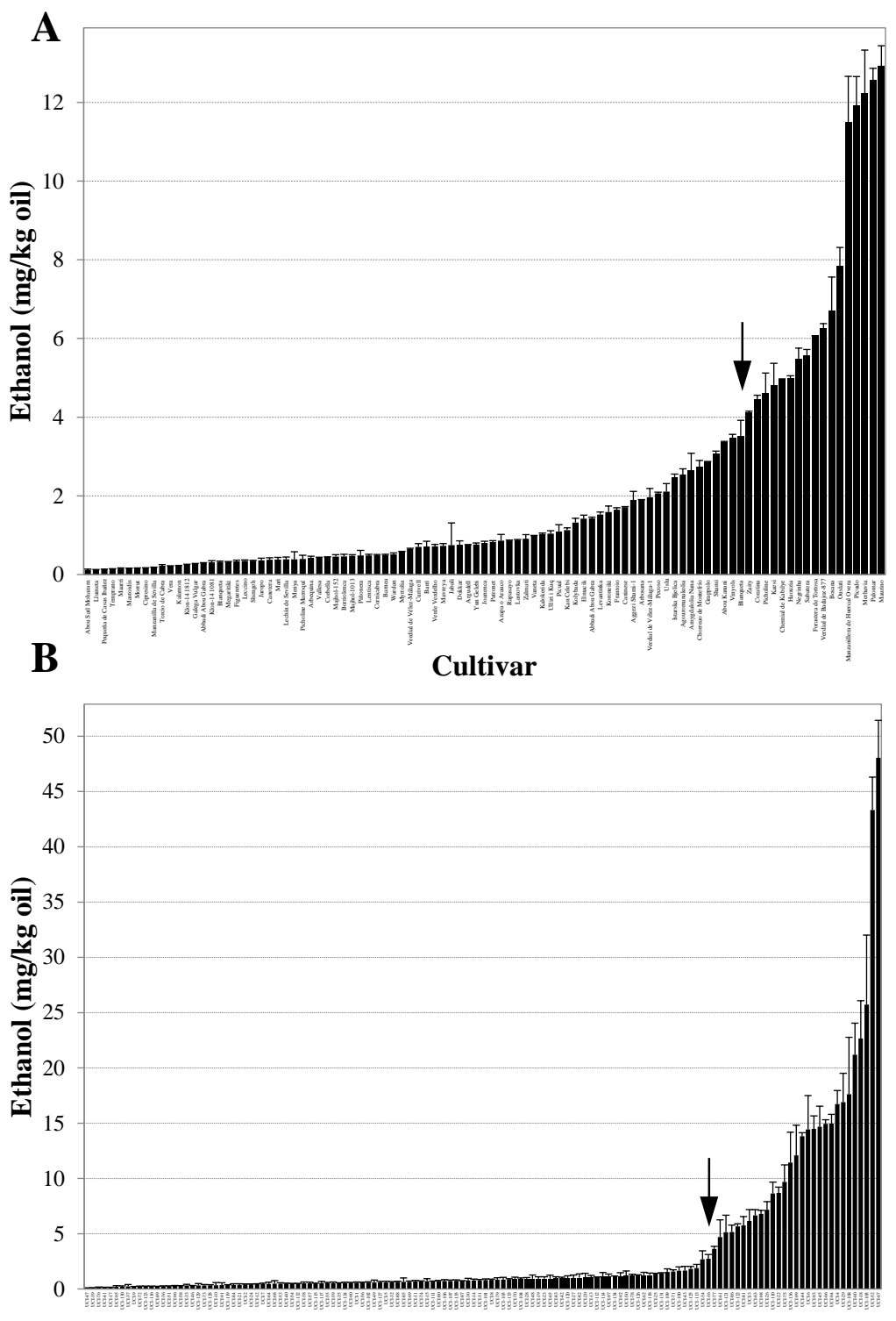

Picual x Arbequina progeny

Figure 2 

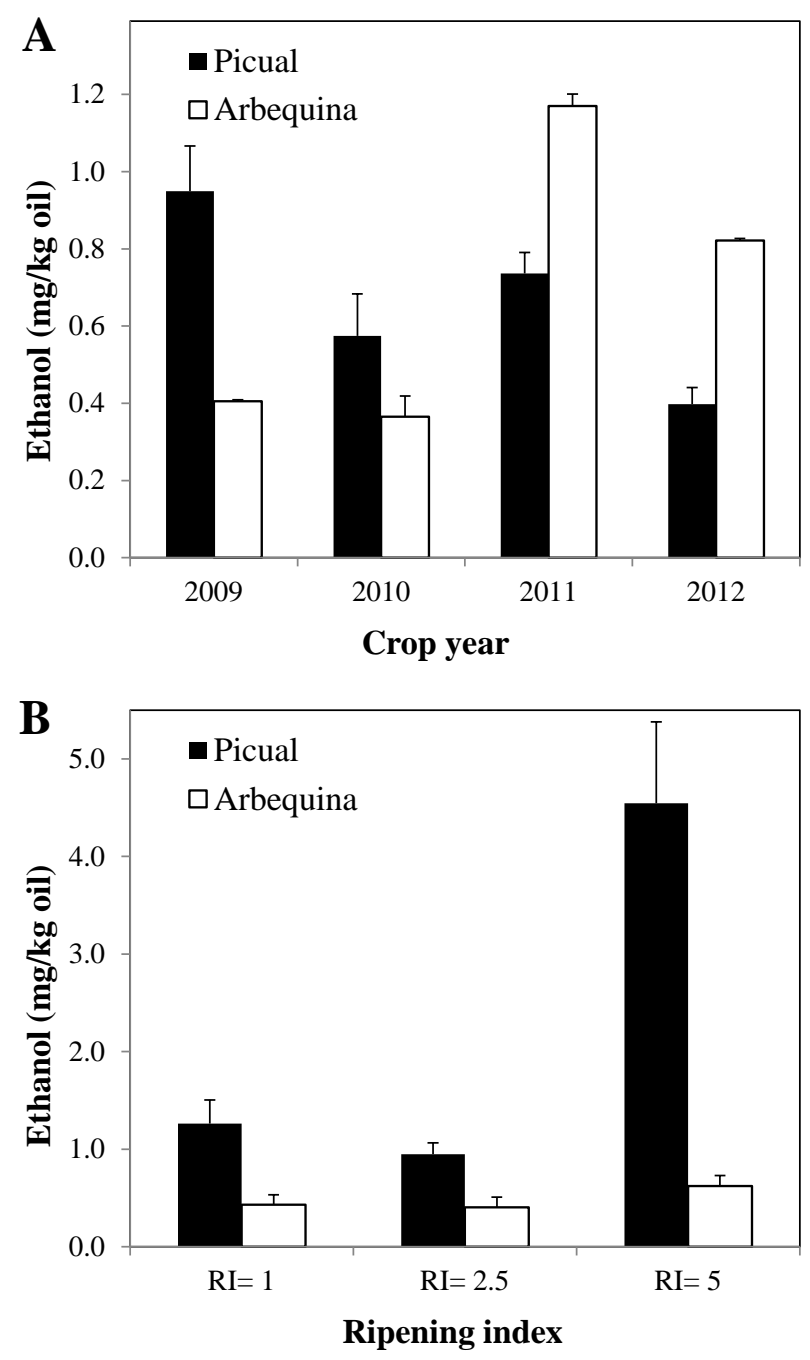

Figure 3 


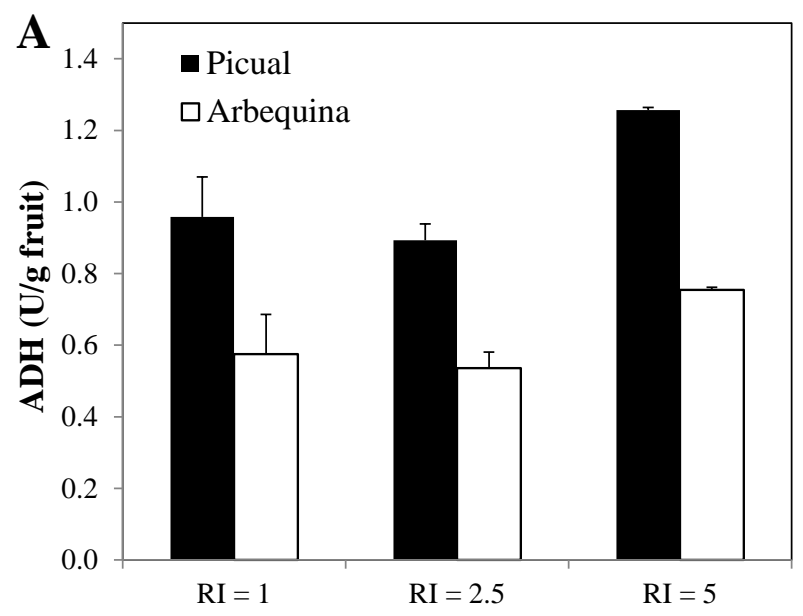

Ripening index

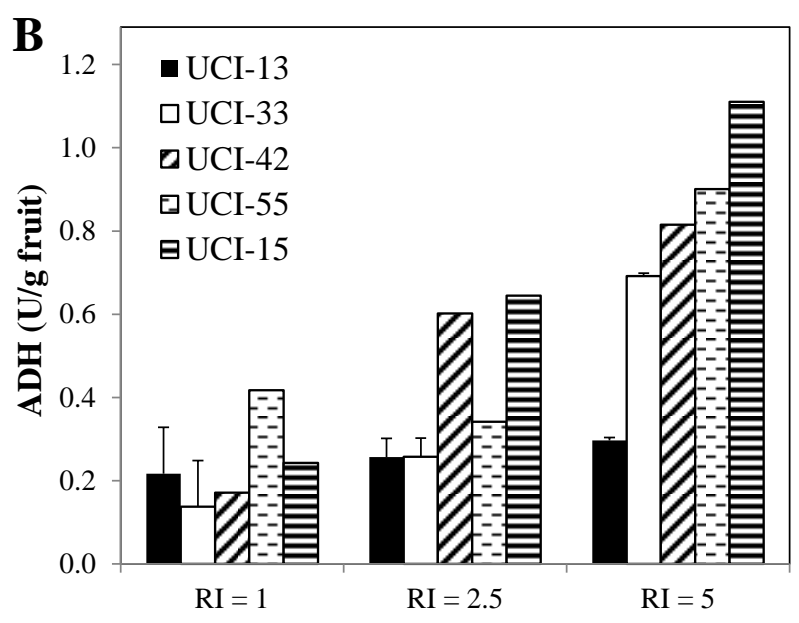

Ripening index

Figure 4 